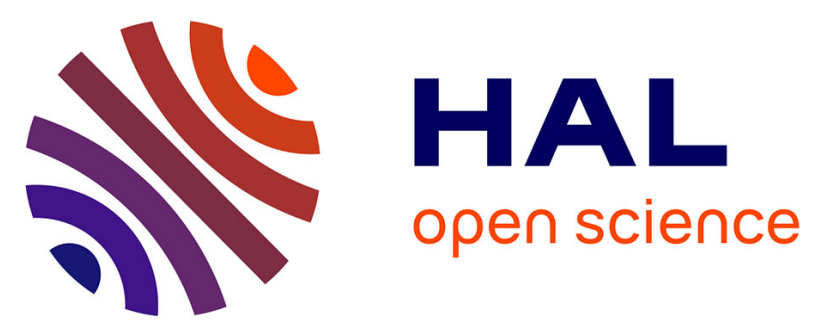

\title{
Increasing Employee Involvement in Socially Sustainable Manufacturing: Two Methods for Capturing Employees' Tacit Knowledge to Improve Manufacturing Processes
} Miia-Johanna Kopra, Nillo Halonen, Eeva Järvenpää, Minna Lanz

\section{- To cite this version:}

Miia-Johanna Kopra, Nillo Halonen, Eeva Järvenpää, Minna Lanz. Increasing Employee Involvement in Socially Sustainable Manufacturing: Two Methods for Capturing Employees' Tacit Knowledge to Improve Manufacturing Processes. IFIP International Conference on Advances in Production Management Systems (APMS), Sep 2015, Tokyo, Japan. pp.539-546, 10.1007/978-3-319-22759-7_62 . hal-01431143

\author{
HAL Id: hal-01431143 \\ https://hal.inria.fr/hal-01431143
}

Submitted on 10 Jan 2017

HAL is a multi-disciplinary open access archive for the deposit and dissemination of scientific research documents, whether they are published or not. The documents may come from teaching and research institutions in France or abroad, or from public or private research centers.
L'archive ouverte pluridisciplinaire HAL, est destinée au dépôt et à la diffusion de documents scientifiques de niveau recherche, publiés ou non, émanant des établissements d'enseignement et de recherche français ou étrangers, des laboratoires publics ou privés.

\section{(ㄷ)(i)}

Distributed under a Creative Commons Attribution| 4.0 International License 


\title{
Increasing Employee Involvement in Socially Sustainable Manufacturing: Two Methods for Capturing Employees' Tacit Knowledge to Improve Manufacturing Processes
}

\author{
Miia-Johanna Kopra, Nillo Halonen, Eeva Järvenpää, Minna Lanz \\ Department of Mechanical Engineering and Industrial Systems, Tampere University of \\ Technology, Korkeakoulunkatu 6, 33720 Tampere, Finland \\ (miia-johanna.kopra, nillo.halonen, \\ eeva.jarvenpaa, minna.lanz) etut.fi
}

\begin{abstract}
Talented workforce is one of the main strengths in Europe to overcome the economic crisis and address the challenges ahead. The most valuable knowledge the employees have, is tacit and, therefore, hard to utilize in the companies. This paper presents two alternative facilitation methods to capture tacit knowledge related to the manufacturing process, thus allowing the employees participate in activities developing the manufacturing process and the development of positive company culture. The first method focuses on operational tacit knowledge, and the latter method extracts the production related tacit knowledge from the project members. Both of the methods use facilitation to guide the employees through the experience-based learning process and provide support for information and knowledge sharing.
\end{abstract}

Keywords: Employee involvement; Socially sustainable manufacturing; Tacit knowledge; Knowledge sharing; Facilitation; Experiential learning; Process development

\section{Introduction}

In the fast changing business environment, persistence in the same operating routines quickly becomes hazardous [1]. The organizations need to learn to adapt their routines, especially if the actions do not produce the intended outcome, or they produce an undesirable outcome. Organizations can learn when they have a shared vision of their aspirations and the future [2]. The vision requires management commitment, which is visible in the investment they made in resources and work processes, supporting learning in the organization [3].

In a socially sustainable corporate culture, the individuals can thrive, continuously develop their talents and use them in the industry [4]. When the work environment is stimulating, the employees are contributing themselves to the development of instructions and knowledge [5]. Internally generated ideas enable the employees to associate more strongly with the task, and to have greater commitment to it [6]. Committed

adfa, p. 1, 2011.

(c) Springer-Verlag Berlin Heidelberg 2011 
employees are motivated and willing to put extra effort in their jobs [7]. As a result, they work more efficiently and improve their organizations' possibilities to succeed.

Also, socially sustainable organizations share knowledge between the organizational units [5]. Such an organization promotes participatory behaviour and encourages the employees to take a broader view on their jobs, and to consider a wider variety of information, inputs and constraints in their decision making process [8]. Organization should fight the Not-Invented-Here (NIH) syndrome and emphasize that everyone can have a good idea [5]. NIH refers to the bias against using knowledge from other sources, i.e. people hesitate to share what they have and to use what others have $[9,10]$. Also, a democratic organizational climate leads to the free exchange of the ideas and to more opportunities for the cross-functional knowledge fertilization, thus preventing localized and isolated problem solving.

This paper presents two alternative facilitation methods, which allow the employees to capture tacit knowledge related to manufacturing process. The employees can participate in activities developing the manufacturing process and the development of positive company culture. Involving the employees in the process development, the company encourages socially sustainable corporate culture, where the employees can develop and use their talents. Also, the employees are invited to contribute to the development of instructions and knowledge. The first method focuses on operational tacit knowledge, and the latter method extracts the production related tacit knowledge from the project members. The methods also support experiential learning in the projects, as well as, information and knowledge sharing in the organization.

\section{Tacit knowledge in organizations}

An increasing number of the organizations use projects and team working to achieve the objectives, and to adapt to the changing business environment. Projects generate a vast amount of knowledge on the organizational processes, as well as, technical knowledge on the products [11]. Created knowledge is mostly tacit in nature and such knowledge cannot be taught, trained or educated, but it can be only learnt and the learning process takes time [13].

Physical face-to-face experiences are the key to conversion and transfer of tacit knowledge [14]. [1] see that by sharing their individual experience and comparing their opinions with those of their colleagues, the project members can achieve an important level of understanding of the causal mechanisms intervening between the actions required to execute a certain task, and of the performance the outcome produces.

The problem of knowing who knows what, grows with the size of the organization and finding a person with relevant tacit knowledge may not be easy [15]. Small companies can list their employees' skills (e.g. related to manufacturing tools) in a spreadsheet and the production supervisor knows the staff, their skills and experiences, based on his experience [16]. Dependency on tacit knowledge only creates a huge risk for the organization. For example, especially small companies do not usually have proper manufacturing IT systems in use. When the manufacturing planning and con- 
trol activities are done based on the tacit knowledge of the production planner or supervisor, then nobody knows how to update the manufacturing plan, if the person is absent. Often the Excel spreadsheets used for production planning and scheduling, are only available and understandable for the person who created them.

Another troublesome aspect of tacit knowledge, is its elusiveness [12]. There may not be effective ways in the organization to elicit tacit knowledge from the individuals, or the organization's culture might actively discourage knowledge sharing, either deliberately or incidentally [17]. Also, people may not be fully aware of their tacit knowledge or they do not have any personal need to make it explicit, or there is a potential risk of losing power and competitive advantage, when making tacit knowledge explicit [12]. Especially in small manufacturing companies, systematic practices for capturing and sharing tacit knowledge are rare [16].

Some authors (e.g. [18]) think that tacit knowledge needs to be made explicit for sharing, thus making codification an essential step in leveraging the value of knowledge in the organization. Knowledge codification allows knowledge to be accessed and used by some others, sometime in the future, and it is not dependent on the personal networking [19]. However, the effort to reduce tacit knowledge nearly always skews knowledge and separates it from its vital context [11].

\section{Learning from the past}

The organization cannot learn from the projects, unless the project members' knowledge is articulated and transferred to the others [20]. Knowledge from project to project flows through direct and detoured transfers [21]. The mediums of direct transfers are mainly employees, who directly move to the next project with knowledge achieved from the previous project. Detoured transfers occur through e.g. knowledge repositories, company manuals, training programs and work processes.

Lessons learned is any form of knowledge, gained from the direct experience, successful or otherwise, to improve the performance in the future [21]. Everyone benefits from reviewing past activities and decisions, to learn what worked, what did not, what can be changed and what must be managed. Usually, the projects are not willing to invest much time in the learning activities, because that time is taken away from other responsibilities, which have a higher priority [9]. Therefore, the learning process needs to be prompted and structured, to be meaningful and useful for the projects.

In most business organizations, failure and fault are virtually inseparable, and examining past activities in depth is emotionally unpleasant and can chip away the individual's self-esteem [22]. In the end, learning from the past is reliant upon the project members' willingness to admit mistakes or deficiencies in their actions, to engage in conversation about those issues, and to subject themselves and their experience to the constructive criticism of their peers [3].

The willingness to expose oneself is related to the perceived quality of their peer relationship. Therefore, the way the project evaluation is facilitated, is crucial [12]. Facilitation is a process in which a person, the facilitator, helps a group of people complete their work and improves the way the group works together [23, 24]. Facili- 
tation can reduce the cultural, professional or organizational barriers, which make communicating difficult [25]. Facilitation also emphasizes learning from the process. This requires that the participants are offered tools to reflect on their experience [24].

\subsection{Capturing operational lessons learned}

A facilitation method was created for capturing the lessons learned in the project teams, to improve the project routines either in the own project (in the later phase of the project) or to propose new ways of working for some other project [26]. The described facilitation method accommodates two approaches to learning: social constructive approach (e.g. [27]) and experiential learning theory (e.g.[28]). It also uses ideas from the model of single-loop and double-loop learning (e.g. [29]), the $4 \mathrm{i}$ framework of organizational learning [30] and the theory of organizational knowledge creation (e.g.[31]).

The facilitation method to capture operational tacit knowledge is divided into three phases: activities prior, during and after the workshop [26]. Prior the workshop, the facilitator and the project leader discuss the facilitation method, the project group, the workshop goals and the practicalities. Workshop activities are illustrated in Figure 1.

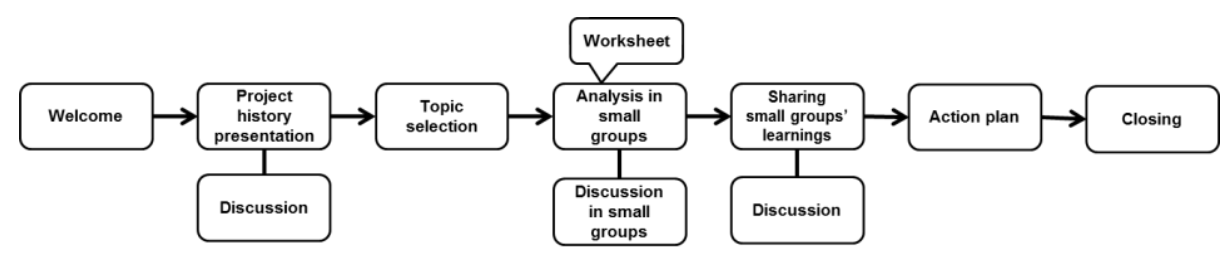

Fig. 1. Phases in lessons learned workshop

The workshop begins with a project history presentation, which defines the timeline of the activities under discussion, as well as, establishes a common ground for the conversations in the workshop. Then, the workshop participants select the topics for further analysis, to be done in the small groups, as well as, the target project for the learnings. The participants decide themselves, which topics are discussed and analysed in small groups. This allows the participants to concentrate on what they believe is important. The analysis includes a scale question related to the project performance and brainstorming ideas. The participants are assigned to small groups and they use a worksheet to document

- Activities and invested resources, which contributed to the project performance concerning the selected topic.

- Activities the project did not perform or resources they did not have, but which could have contributed to the project's success.

They also describe how they would have acted if they had the knowledge they currently have and all the resources available. The template guides the participants to convert their tacit knowledge into explicit, and document it. Each small group pre- 
sents their analysis and the others have a possibility to comment on the results. Then, the participants plan how they are going to proceed with the captured lessons learned.

After the workshop, the project implements the agreed plan, and either transfers the learnings to the identified target project, or uses the improvement ideas to modify the project's own routines. The participants review the meeting minutes and the minutes they are made available for others in the organization. The captured lessons learned and the improvement ideas are also delivered to the function or team responsible for the operational development in the organization, because the ideas can be used in improving the organizational routines.

Example A: A manufacturing project was preparing for mass-production phase. Members from the target project, i.e. a similar manufacturing project in their early phase, were invited to the workshop to ensure efficient knowledge transfer. The project was the first of a kind in the organization, and there had been many challenges and issues, which the participants wanted to discuss. The analysed topics were related to the product data management and the cooperation with the customer. The created improvement ideas formed a basis for a discussion related to the needed changes in the operational mode to support the new type of projects.

\subsection{Capturing production related knowledge}

In this facilitation method, the project members model and analyse the production process and share their experiences on the production using Design Reasoning Pattern (DRP) principles [32]. With the help of a facilitator, the participants make the production phases and sub-deliverables explicit by modelling the existing production process into logical information flow and focusing only on value adding elements. The method is divided into six phases, which can be divided into several workshops. Phases in the method are illustrated in Figure 2.

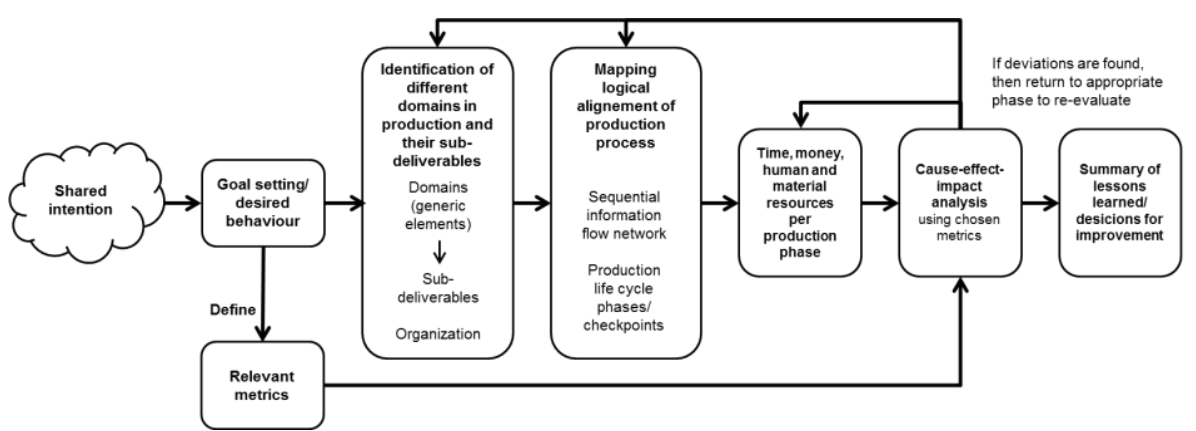

Fig. 2. Phases in the Design Reasoning Method

First, the participants define the goals for the analysis. Then, the broader domains (i.e. functional areas of the production or organizational areas), list of subdeliverables for each domain and the design decision elements are mapped. In the third phase, the identified elements are aligned into a process description by dividing 
the sub-deliverables into life cycle phases and linking deliverables into a logical sequential flow. Also, the relevant checkpoints in the production are defined.

In the fourth phase of the method, the participants define time, money, human and material resource allocations into production phases, to identify the whole spectrum of production process' information, material, work and control flows and the critical path of the process. Then, the explicit production process is analysed with chosen metrics (e.g. how much of the current errors in the production are caused by lack of information of right product specifications or by inefficient information transfer within production process or what are critical production phases to be improved). Finally, the participants are able to identify the important learnings, the points of potential improvement in the production process and the solutions to make the improvements happen.

Creating the logical relations between the design elements allows the participants to develop a shared understanding regarding the production process. More importantly, by joining the different experiences of the participants together not just makes tacit knowledge explicit, but creates totally new knowledge for participants. DRP also helps the project to create a common language which, in turn, facilitates knowledge sharing in the project.

Example B: A company was trying to find the root cause for a problem in a new manufacturing line. The problem solving had already taken over 1700 man hours and the root cause for the problem was still unknown. Then, the company used 70 man hours to create a model with the DRP method and re-test the manufacturing process. The root cause for the problem was located outside the scope the quality system related parameters. The company estimated that the created DRP model was worth of one man year of labour.

\section{Conclusions}

Both facilitation methods support the idea of learning organization, which is seen as one of the important aspects of socially sustainable manufacturing. If the employees learn from their experience, then they can suggest modifications to the ways of working. Additionally, the employees are involved in defining the routines they ought to follow. Presented facilitation methods increase tacit knowledge sharing, as well as, enhance communication and openness in the organization, thus leading to better understanding of the whole, i.e. how a person's work and decisions affect to everything else. The methods also support shared leadership in projects and provide better possibilities for employee involvement, as all project members can contribute to defining common plans or ways of working. This, in turn, increases employees' motivation and commitment to the organization, and provides opportunities for the organization to succeed.

In manufacturing companies, capturing lessons learned can be used to suggest the most effortless, yet effective, ways of working or to agree common rules. Design reasoning patterns produce new system level knowledge and enhance the employees' understanding regarding the manufacturing functionalities and the dependencies be- 
tween them. For example, it has been noted that in the production environment the production operators are not able to make self-directed decisions e.g. related to the feasible order of the jobs. This is partly due to the lack of real time information transparency (IT system issue) but also lack of understanding of the whole. Therefore, making the factory floor workers to participate to such facilitated sessions could be beneficial for the company to enhance the production to flow and to reduce lead time.

The presented methods could be combined so, that the production development needs are analysed with the DRP method and then, as part of the change process, the earlier production changes are analysed with lessons learned method to find out the most effective ways of implementing changes. However, the methods require a supporting organizational culture, which may not be present in the small manufacturing companies at the moment. Also, the DRP method might be too complex for a small manufacturing company which does not have own product development functions. Additionally, the methods do not directly enhance the availability of production related information needed for design for manufacturing, design for assembly and design for assembly automation.

\section{$5 \quad$ References}

1. Zollo, M., Winter, S.G.: Deliberate Learning and the Evolution Dynamic Capabilities. Organization Science, 13(3), pp. 339-351 (2002).

2. Senge, P.M. The Fifth Discipline: The art \& practice of the learning organization. Doubleday Business (1990).

3. Sense, A.J.: Facilitating conversational learning in a project team practice. Journal of Workplace Learning, 17(3), pp. 178-193 (2005).

4. Fantini, P., Pinzone, M., Taisch, M.: Preliminary findings from the Socially Sustainable Manufacturing Ecosystems Workshop. July 24, 2014. Available from: http://www.pearltrees.com/s/file/preview/91187197/SOSMARTworkshop1Milano30jun201 4.pdf [Accessed 18-03-2015].

5. Berlin, C., Barletta, I.: Preliminary findings from the 2nd Socially Sustainable Manufacturing Ecosystems Workshop. September 16, 2014. Available from: http://www.pearltrees.com/s/file/preview/96660588/SOSMARTworkshop2GteborgSep1620 14.pdf [Accessed 18-03-2015].

6. Kessler, E.H., Bierly, P.E. and Gobapakrishnan, S.: Internal vs. external learning in new product development: effects on speed, costs and competitive advantage. R\&D Management, 30(3), pp. 213-223 (2000).

7. Lin, C.: To share or not to share: modeling knowledge sharing using exchange ideology as a moderator. Personnel Review, 36(3), pp. 457-475 (2007).

8. Sarin, S. and McDermott, C.: The Effect of Team Leader Characteristics on Learning, Knowledge Application, and Performance of Cross-Functional New Product Development Teams. Decision Sciences, 34(4), pp. 707-739 (2003).

9. O'Dell, C., Grayson, C.J.: If Only We Knew What We Know: Identification and Transfer of Internal Best Practices. California management review, 40(3), pp. 154-174 (1998).

10. von Krogh, G., Ichijo, K. and Nonaka, I.: Enabling knowledge creation: how to unlock the mystery of tacit knowledge and release the power of innovation. Reprint edition. Oxford University Press (2000) 
11. Goffin, K., Koners, U., Baxter, D., Van, D.H.: Managing Lessons Learned and Tacit Knowledge in New Product Development. Research Technology Management, 53(4), pp. 39-51 (2010).

12. Stenmark, D.: Leveraging Tacit Organization Knowledge. Journal of Management Information Systems, 17(3), pp. 9-24 (2001).

13. Haldin-Herrgard, T.: Difficulties in diffusion of tacit knowledge in organizations. Journal of Intellectual Capital, 1(4), pp. 357-365 (2000).

14. Nonaka, I., Konno, N.: The Concept of "Ba": Building a Foundation for Knowledge Creation. California Management Review, 40(3), pp. 40-54 (1998).

15. Smith, E.A.: The role of tacit and explicit knowledge in the workplace. Journal of Knowledge Management, 5(4), pp. 311-321 (2001).

16. Järvenpää, E., Lanz, M., Tokola, H., Salonen, T., Koho, M.: Production planning and control in Finnish manufacturing companies: Current state and challenges. Proceedings of International Conference on Flexible Automation and Intelligent Manufacturing (FAIM), Wolverhampton, June 23-26, University of Wolverhampton (2015).

17. Falconer, L.: Organizational learning, tacit information, and e-learning: a review. Learning Organization, 13(2), pp. 140-151 (2006).

18. Nonaka, I.: A Dynamic Theory of Organizational Knowledge Creation. Organization Science, 5(1), pp. 14-37 (1994).

19. Newell, S., Edelman, L.F.: Developing a dynamic project learning and cross-project learning capability: synthesizing two perspectives. Information Systems Journal, 18(6), pp. 567591 (2008).

20. Riege A.: Three-dozen knowledge-sharing barriers managers must consider. Journal of Knowledge Management, 9(3), pp. 18-35 (2005).

21. Jeon, J.: Success Factors for a Lessons-Learned System in a Construction Organization. Cost Engineering, 51(5), pp. 13-20 (2009).

22. Edmondson, A.C.: Strategies For Learning From Failure. Harvard Business Review, 89(4), pp. 48-55 (2011).

23. Farrell, J., Weaver, R.: Facilitation: A formula for success. Journal for Quality \& Participation, 21(5), pp. 44-48 (1998).

24. Herbert, A.: Facilitator, Researcher, Politician, Magician. Simulation \& Gaming, 41(5), pp. 681-693 (2010).

25. Kolb, J.A.: Initial contracting issues in small group facilitation. Industrial \& Commercial Training, 36(5), pp. 207-209 (2004).

26. Kopra, M-J. 2012. Facilitating Experience-based Learning in Groups: A Method for Capturing Lessons Learned. Dissertation, Institute for Business Information Management and Logistics, Tampere University of Technology (2012).

27. Siljander, P.: Systemaattinen johdatus kasvatustieteeseen. 2nd edn. Otava (2005).

28. Kolb, D.A.: Experiential learning: experience as the source of learning and development. Prentice Hall (1984).

29. Argyris, C.: On Organizational Learning. 2nd ed. Wiley-Blackwell (1999).

30. Crossan, M.M., Lane, H.W. and White, R.E.: An Organizational Learning Framework: from Intuition to Institution. Academy of Management Review, 24(3), pp. 522-537 (1999).

31. Nonaka, I. and Takeuchi, H.: The knowledge-creating company: how Japanese companies create the dynamics of innovation. Oxford University Press (1995).

32. Halonen, N., Lehtonen, T., Juuti, T., Ellman, A,: Impacts of making design sequence explicit on NPD project in forest machinery company. Proceedings of NordDesign 2014 Conference, Espoo/Melbourne, August 27-29, Aalto University/Swinburne Design Factory (2014). 